\title{
Evolução recente das planícies de marés nas desembocaduras dos rios Sergipe e Vaza Barris, Sergipe
}

\author{
Recent developments in tidal plains in the mouths of Sergipe and Vaza Barris rivers, \\ Sergipe
}

Rosemeri Melo e Souza

$\operatorname{Prof}^{\mathrm{a}} \mathrm{Dr}^{\mathrm{a}}$ Associada do Departamento de Engenharia Ambiental

e PPGEO - Universidade Federal de Sergipe rome@ufs.br

Geisedrielly Castro dos Santos Doutora em Geografia pela Universidade Federal de Sergipe geisecastrosantos@hotmail.com

\begin{abstract}
Resumo
O objetivo do presente trabalho foi analisar a evolução das planícies de marés nas desembocaduras dos rios Sergipe e Vaza Barris no estado de Sergipe. Os principais procedimentos metodológicos foram: processamento das imagens de satélite e fotografias aéreas; vetorização das classes temáticas e da linha de costa; quantificação e sobreposição das linhas de costas mapeadas. Os resultados obtidos mostraram que em ambas as desembocaduras a formação da planície de maré foi recente. Verificou-se redução da feição geomorfológica nas duas desembocaduras, contudo com processos diferenciados. Na desembocadura do rio Sergipe a redução da planície de maré foi promovida pelas ações antrópicas de urbanização da Coroa do Meio em Aracaju/SE, e na desembocadura do rio Vaza Barris, em Itaporanga D’Ájuda, o fator condicionante foi o recuo de linha de costa. A realização desta pesquisa auxilia no monitoramento das respostas dos ambientes costeiros a mudanças costeiras em escalas local e global.
\end{abstract}

Palavras-chave: Dinâmica fluviomarinha, Ações antrópicas, Linha de costa.

\begin{abstract}
The aim of this study was to analyze the evolution of the tidal flats in the mouths of Sergipe and Vaza Barris rivers in the state of Sergipe. The main methodological procedures were: of satellite imaging and aerial photographs; vectorization of thematic classes and the shoreline; quantification and overlay of mapped back lines. The results showed that in both mouths training tide flat was recent, but there was a reduction of geomorphological feature in the two mouths, but with different processes. At the mouth of the Sergipe river reducing tide plain was promoted by anthropogenic actions of urbanization of Coroa do Meio in Aracaju / SE, and at the mouth of the Vaza Barris river, in Itaporanga D'ajuda, the determining factor was the retreat of the shoreline. This research contributes to the monitoring of the responses of coastal environments to coastal changes in local and global scales.
\end{abstract}

Keywords: Fluviomarine dynamics, Anthropogenic actions, Shoreline. 


\section{INTRODUÇÃO}

Nas regiões costeiras, os ambientes de sedimentação foram formados a partir das oscilações do nível do mar durante o período Quaternário, as formas mais recentes surgiram no Holoceno, a menos de 10.000 A.P. (MARTIN; SUGUIO; FLEXOR, 1993). Os sistemas ambientais que se originam nas regiões costeiras possuem extrema complexidade, tendo em vista que são regidos por componentes de origem atmosférica, oceanográfica, fluvial e terrestre. Um dos exemplos desses ambientes são as planícies de marés, já investigadas em várias partes do mundo e com estimativas de deposição do pacote sedimentar relacionadas às transgressões e regressões marinhas, correspondendo a sistemas ambientais de extrema variabilidade (WOODROFFE, 1982; BITTENCOURT et al, 1983).

As planícies de marés ocorrem em todo o mundo, em geral nas reentrâncias costeiras localizadas em zonas estuarinas, determinadas por condições únicas dos componentes geomórficos, geofísicos e biológicos (THOM, 1982). Quando esses ambientes de sedimentação (ou substratos lamosos) ocorrem em associação com vegetações do tipo halófitas conhecidas como mangues, temse a formação de ecossistemas manguezais. Para que os manguezais se desenvolvam é necessário, de acordo com Chapman (1975), que ocorram 7 requisitos básicos: Temperatura do ar preferencialmente entre $20^{\circ} \mathrm{C}$ e $5^{\circ} \mathrm{C}$; Correntes marítimas mais quentes; Áreas protegidas da ação mecânica das ondas como lagunas e baías costeiras; Água salgada; Regime de marés e Substrato lamoso.

Mesmo reconhecendo que a origem da maioria das planícies de marés ocorreu ao longo do Quaternário é possível verificar a formação desses ambientes em um período mais recente, em escala de médio prazo (cerca de décadas) e de curto prazo (meses e anos), sendo determinadas pela disponibilidade de sedimentos e pelas condições estuarinas locais.

A Área de estudo do presente artigo corresponde às planícies de marés desenvolvidas na margem direita das desembocaduras dos rios Sergipe - município de Aracaju-SE e Vaza Barris município de Itaporanga D’Ájuda-SE (Figura 1).

Os processos de formação das referidas desembocaduras foram explicados por diversos autores. Para a margem direita da desembocadura do rio Sergipe a análise evolutiva das cartas náuticas, a partir do ano de 1891 até o ano de 1924, demonstrou a existência de duas coroas arenosas. Essas coroas arenosas possuíam inúmeros canais de maré, sendo divididas por três canais principais (Norte, Central e Sul), por onde o rio Sergipe entrava em contato com o Oceano Atlântico. Devido à dinâmica fluviomarinha no local, emergiram de forma gradativa nas coroas alguns pontais arenosos, sendo estes os responsáveis pela consolidação das duas coroas e posterior ligação ao município de Aracaju pela restinga existente no bairro Atalaia (chamado à época de 
Pontal Sul). A consolidação das coroas arenosas permitiu o alargamento do canal Norte, fechando o canal Central e isolando o canal Sul (MONTEIRO, 1963; WANDERLEY, 2006; SANTOS, 2012; SANTOS, 2014) - Figura 2. Esse processo evolutivo é compatível com a proposição de FitzGerald; Kraus e Hands (2000) para o modelo de transpasse de sedimentos denominado rompimento do delta de maré vazante (ebb-tidal delta breaching) representado na Figura 3.

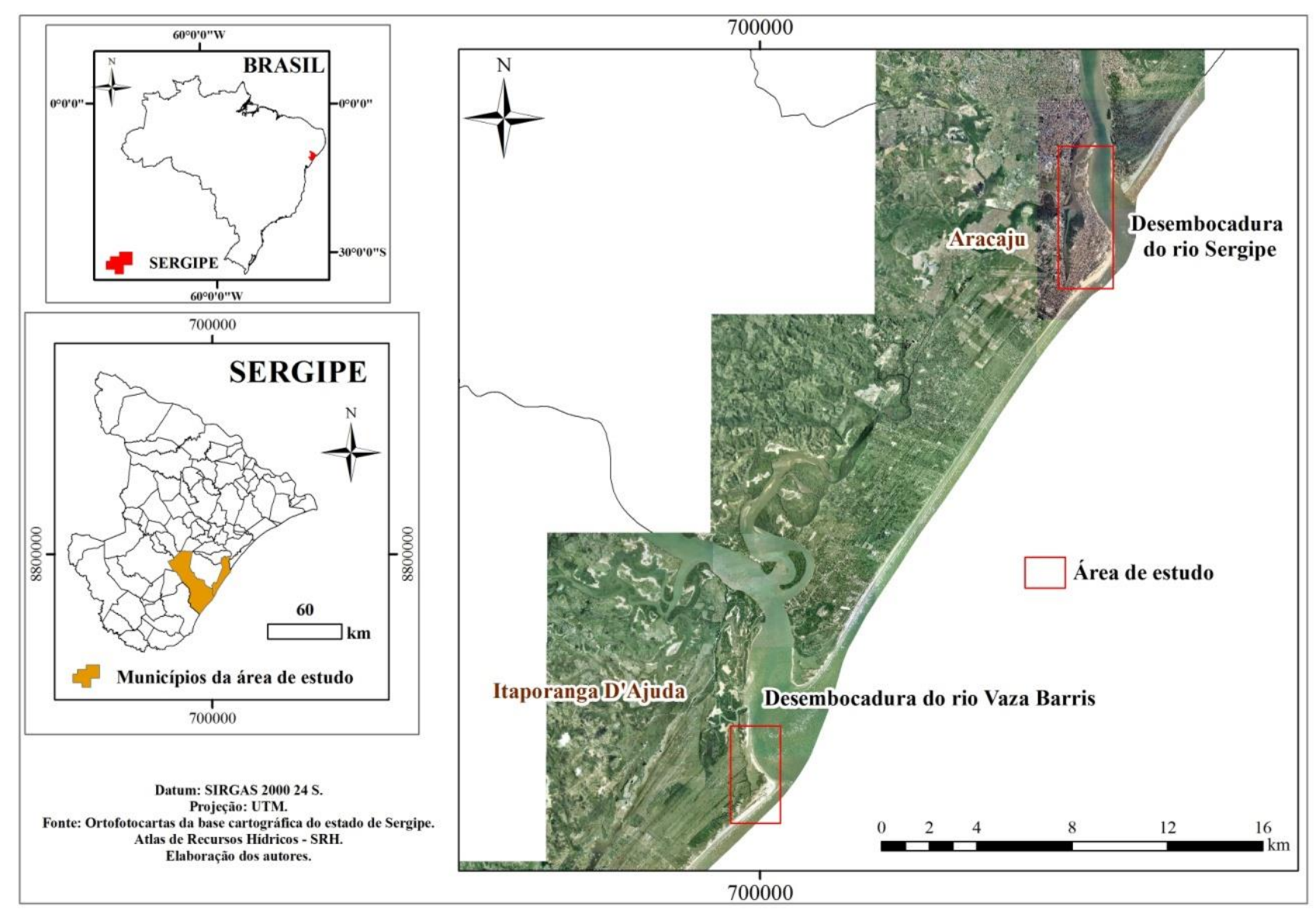

Figura 1 - Localização da área de estudo.

Fonte: Elaboração dos autores.

A margem direita da desembocadura do rio Vaza Barris foi analisada por Oliveira e Melo e Souza (2015). De acordo com as autoras a formação da área de estudo segue o modelo de quebra da plataforma do pontal arenoso (Spit Plataforma breaching). Este modelo ocorre em canais migratórios, onde a formação de um canal secundário na desembocadura promove o rompimento na plataforma do pontal arenoso, sendo que este novamente sofre acresção a partir do fornecimento de sedimentos existentes nos deltas de maré vazante e promovem a contínua migração do canal. Com a erosão do Pontal arenoso a Updrift (barlamar do sentido da deriva litorânea, equivalente à margem esquerda da desembocadura) os sedimentos acumularam-se dando origem ao pontal arenoso a Downdrift (sotamar do sentido da deriva, equivalente a margem direita da desembocadura). $\mathrm{O}$ referido modelo está representado na Figura 4. 

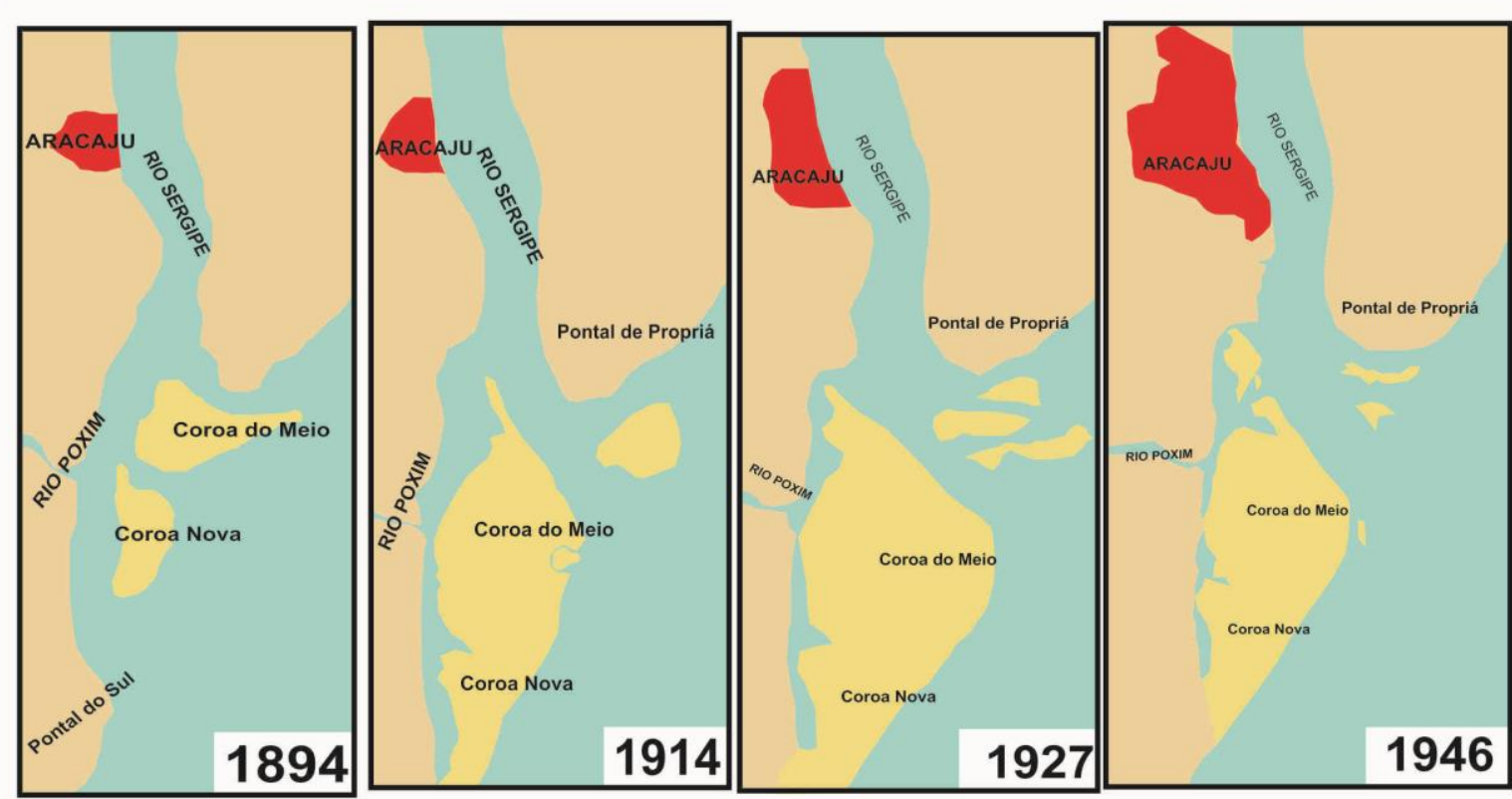

MANCHA URBANA

Figura 2 - Formação da Coroa do Meio na desembocadura do rio Sergipe. Modificado das cartas náuticas doa anos de 1894,1914,1927 e 1946.

Fonte: Elaboração da autora.

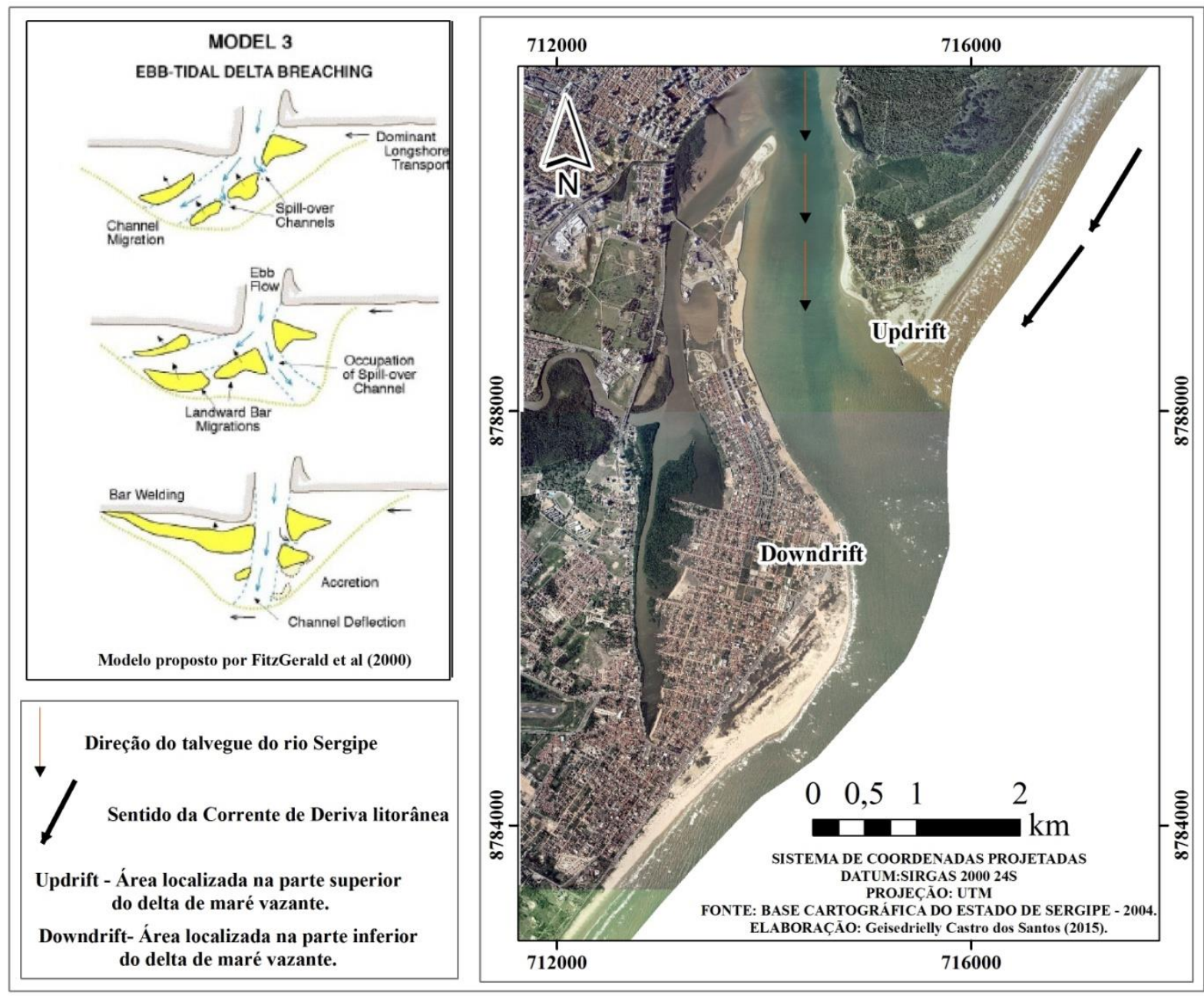

Figura 3 - Modelo de rompimento do delta de maré vazante para o rio Sergipe.

Fonte: Elaboração da autora. 


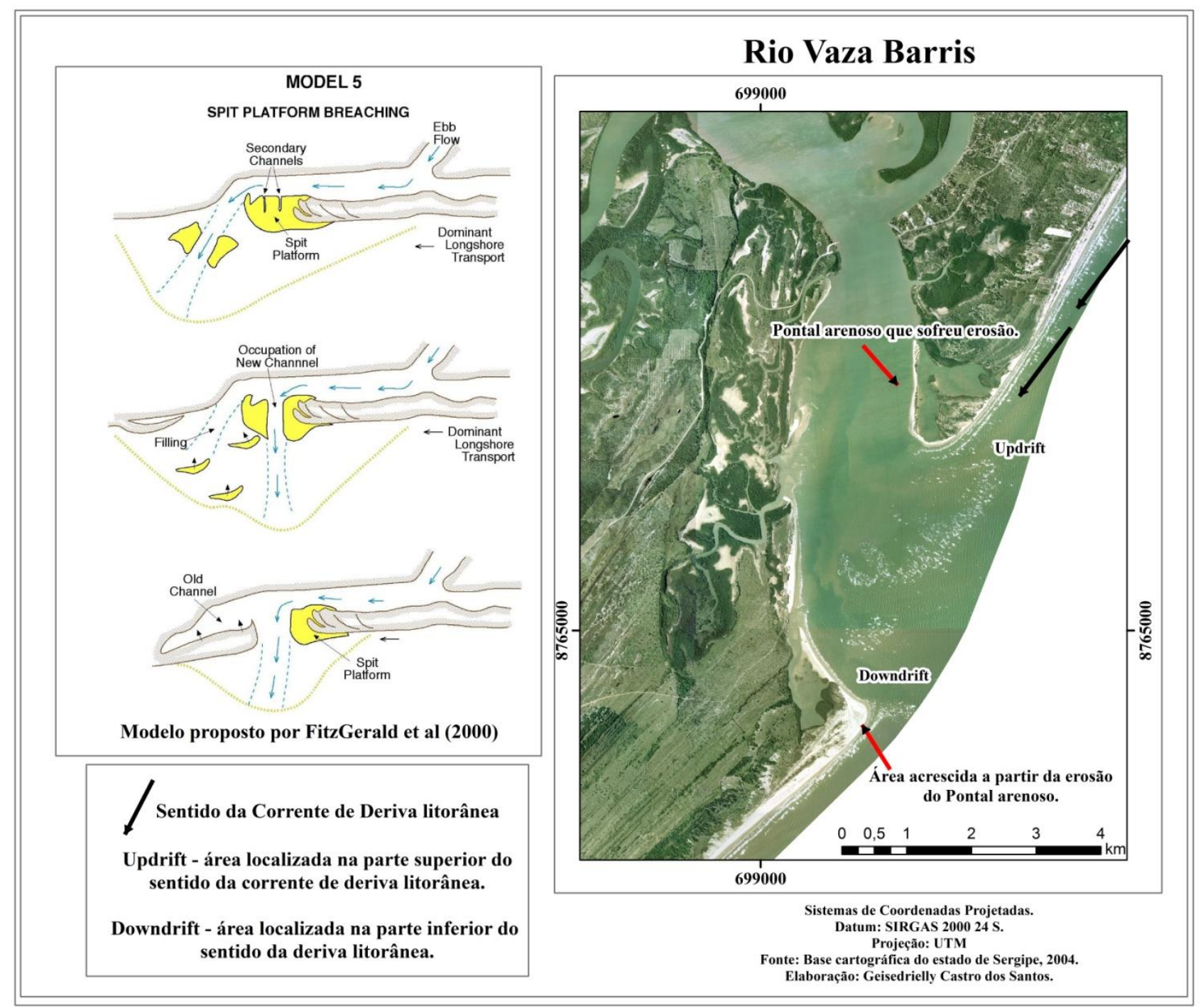

Figura 4 - Modelo de quebra da plataforma do pontal arenoso na desembocadura do rio Vaza Barris. Fonte: Elaboração da autora.

Nesse contexto de modelagem das desembocaduras evoluíram as planícies de marés, analisadas no presente trabalho, que tem por objetivo analisar a evolução recente das planícies de marés e principais fatores condicionantes físicos e antrópicos.

\section{MATERIAIS E MÉTODOS}

Para a realização do presente trabalho foram efetuadas as seguintes etapas metodológicas:

\subsection{Aquisição e processamento das imagens de satélite e fotografias aéreas:}

A análise multitemporal para esta pesquisa consistiu no melhor instrumento para verificar o funcionamento e a dinâmica da área de estudo. Para sua execução foram utilizadas imagens do satélite Quickbird de alta resolução do ano de 2014, adquiridas e cedidas pela Empresa Municipal 
de Obras e Urbanização - EMURB/SE, Imagens do satélite Rapideye de 2014, cedidas pelo Ministério do Meio Ambiente e Fotografias aéreas dos anos de 1955,1965, 1971,1984 e 2004 cedidas pela Secretaria de Planejamento Orçamento e Gestão - SEPLAG/SE.

O processamento das imagens de satélite e das fotografias aéreas foi dividido em duas etapas: retificação do datum horizontal e do georeferenciamento.

No SIG ArcGis v.12.2.1 foram feitas as importações das imagens de satélite e das fotografias aéreas. Posteriormente foi feita a correção do datum horizontal de SAD 1969 para SIRGAS 2000.

Após a retificação do datum foi feita a retificação do georeferenciamento das imagens de satélite utilizando como referência as fotografias aéreas do ano de 2004, executadas pela SEPLAG/SE e que compõem a base cartográfica do estado de Sergipe. O georeferenciamento foi efetuado com auxílio do SIG QuantumGis v.2.0.1. Essa etapa permitiu que as imagens de satélites e as fotografias aéreas pudessem ser sobrepostas quando necessário, a fim de facilitar a análise evolutiva.

\subsection{Vetorização, criação dos arquivos em shapefile e confecção dos mapas temáticos.}

No SIG ArcGis v.12.2.1 foi efetuada a criação das classes temáticas no formato shapefile (.shp). As principais classes temáticas vetorizadas foram: Planície de maré sem colonização por mangue; Mangue; Praia e Linha de Costa. Após a vetorização das classes temáticas e posterior criação dos polígonos e linhas foi realizada a medição da área das classes temáticas: Planície de maré sem colonização por mangue; Mangue e Praia. A medição foi efetuada observando os valores de área de cada polígono, presentes na tabela de atributos de cada classe. Os mapas temáticos tiveram como objetivo representar os principais elementos da área de estudo. Foram realizados para esta pesquisa mapeamentos relativos aos anos de 1971, 1984 e 2014 para a desembocadura do rio Vaza Barris e dos anos de 1955, 1965 e 2014 para a desembocadura do rio Sergipe. A escolha dos períodos deveu-se a disponibilidade de material para as referidas áreas.

Para a vetorização da Linha de costa utilizou-se como indicador a linha de maré alta (High Water Line), que separa a praia seca da área úmida. Este indicador é muito utilizado para determinação da linha de costa por ser de fácil identificação em imagens de satélite e/ou fotografias aéreas e por possuir boa continuidade ao longo da área de estudo (PAJAK; LEATHERMAN, 2002). Foi efetuado o levantamento da linha de costa para a margem direita da desembocadura do rio Vaza Barris a fim de verificar a sua relação com a evolução da planície de maré. Posteriormente foi confeccionado o mapa temático de evolução da linha de costa a partir da sobreposição das linhas de costas dos anos de 1971, 1984, 2004 e 2014. 


\section{RESULTADOS E DISCUSSÃO}

Conforme demonstrado na introdução deste trabalho, as desembocaduras que compõem a área de estudo foram modeladas a partir de processos de transpasse de sedimentos, condicionados pela dinâmica estuarina e dinâmica dos deltas de maré vazantes. Mesmo sendo modeladas a partir de processos diferenciados de transpasse formaram-se em ambas as desembocaduras lagunas costeiras. Essas feições geomorfológicas são caracterizadas nessa situação por receber aporte sedimentar e fluxo hídrico tanto de origem fluvial quanto marinha, ambiente ideal para desenvolvimento de planícies de marés (ZENKOVICH, 1967; ANGULO, 1990).

A primeira identificação da formação da Planície de maré na desembocadura do rio Sergipe foi verificada no ano de 1955 (Figura 5 - A). A referida planície de maré formou-se quando o ambiente lagunar ficou resguardado da ação direta das ondas, fato que ocasionaria o contínuo retrabalhamento dos sedimentos do substrato e possível perda para a dinâmica estuarina, não sendo possível sua estabilização. Levando-se em consideração que as análises realizadas a partir das cartas náuticas revelaram que a partir de 1914 a feição lagunar já havia sido formada (WANDERLEY, 2006; SANTOS, 2012), é possível concluir que essa planície de maré se formou em um período de 41 anos, no mesmo período ocorreu à estabilização dos sedimentos e assim promovendo a fixação do mangue. De acordo com a Tabela 1, no ano de 1955 a área total correspondente à Planície de maré era de $3,22 \mathrm{~km}^{2}$ e a área que corresponde somente ao mangue era de $1,05 \mathrm{~km}^{2}$.

No ano de 1965 a área da Planície de maré e do mangue na desembocadura do rio Sergipe se expandiu, passando a ocupar uma área de $3,71 \mathrm{~km}^{2}$ e $2,20 \mathrm{~km}^{2}$ respectivamente (Figura 5 - A e Tabela 1). Toda essa área expandida começou a se retrair nos anos subsequentes, essa constatação foi apontada por Santos (2012) que atribui à expansão da ocupação humana sobre a Coroa do Meio como fator determinante para a descaracterização da planície de maré e consequentemente do manguezal. As principais ações antrópicas sobre a Coroa do Meio atuaram no sentido de aterrar grande parte do substrato para implantação de edificações com fins de moradia e aparatos de lazer, fato que se iniciou na década de 1970 com a urbanização do bairro no município de Aracaju. Como resultado dessas intervenções antrópicas em 2014 verificou-se uma redução de $48 \%$ na área total da Planície de maré, e uma redução na área colonizada por mangue de quase $1 \mathrm{~km}^{2}$, em dados brutos a área de Planície de maré nesse ano foi de $1,95 \mathrm{~km}^{2}$ e de $1,29 \mathrm{~km}^{2}$ de mangue.

O processo evolutivo da planície de maré na desembocadura do rio Vaza Barris foi verificado a partir de 1971 com a formação de uma pequena área de planície de maré na porção interna da laguna, contudo já se observava colonização pelo mangue. A área total da planície de maré nesse ano era de $0,11 \mathrm{~km}^{2}$ e da colonização por mangue de $0,04 \mathrm{~km}^{2}$ (Figura 5 - B e Tabela 1). 


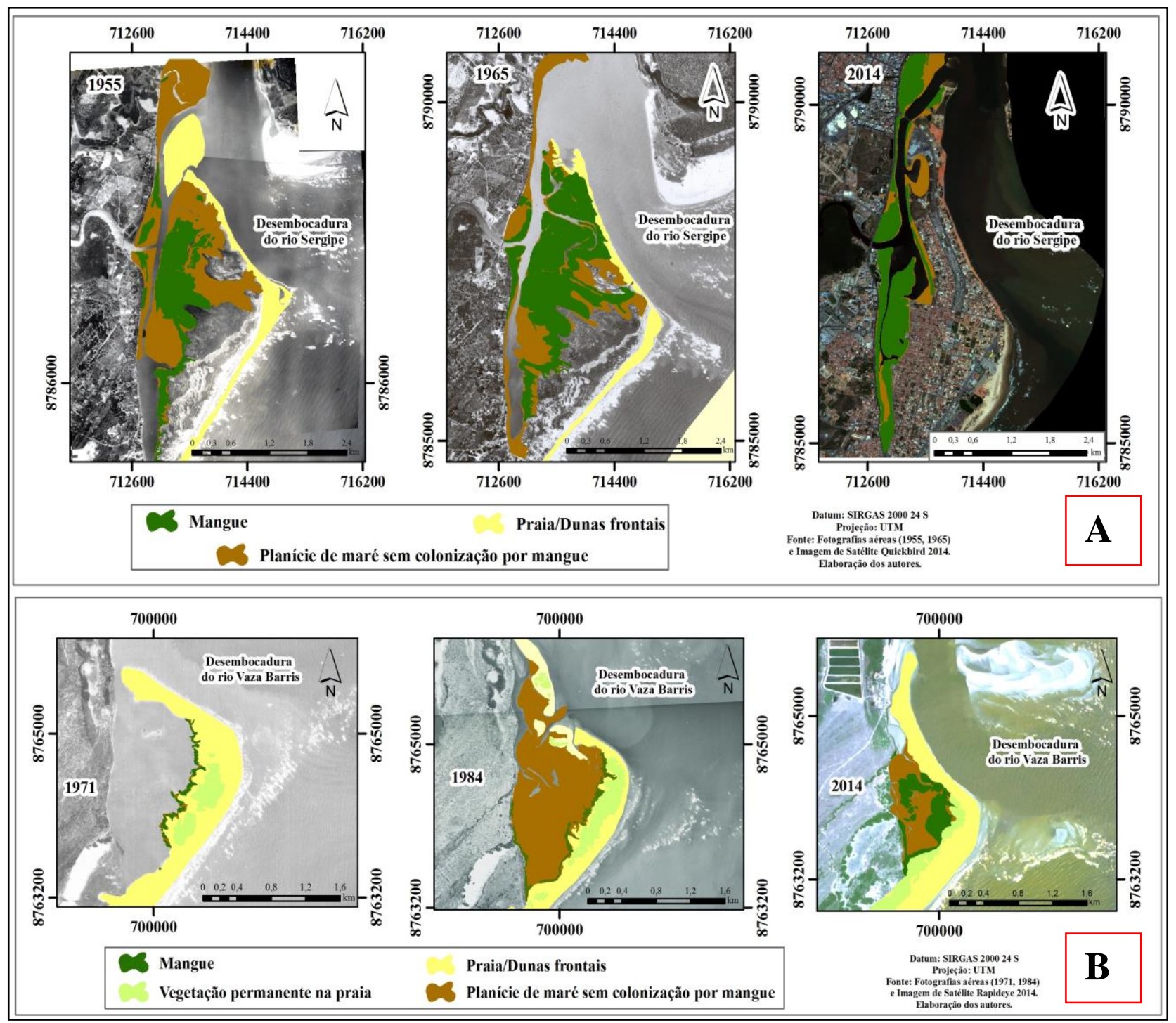

Figura 5 - Evolução das Planícies de marés e Manguezais nas desembocaduras dos rios Sergipe e Vaza Barris. Fonte: Elaboração da autora.

Tabela 1 - Área das Planícies de marés desprovidas de mangue e da área colonizada por Mangue.

\begin{tabular}{ccc|ccc}
\hline \multicolumn{2}{c}{ Desembocadura do rio Sergipe } & \multicolumn{2}{c}{ Desembocadura do rio Vaza Barris } \\
\hline & $\begin{array}{c}\text { Mangue } \\
\left(\mathrm{km}^{2}\right)\end{array}$ & $\begin{array}{c}\text { Planície de maré } \\
\left(\mathrm{km}^{2}\right)\end{array}$ & $\begin{array}{c}\text { Mangue } \\
\left(\mathrm{km}^{2}\right)\end{array}$ & $\begin{array}{c}\text { Planície de maré } \\
\left(\mathrm{km}^{2}\right)\end{array}$ \\
\hline $\mathbf{1 9 5 5}$ & 1,05 & 3,22 & $\mathbf{1 9 7 1}$ & 0,04 & 0,11 \\
$\mathbf{1 9 6 5}$ & 2,20 & 3,71 & $\mathbf{1 9 8 4}$ & 0,08 & 1,63 \\
$\mathbf{2 0 1 4}$ & 1,29 & 1,95 & $\mathbf{2 0 1 4}$ & 0,23 & 0,54 \\
\hline
\end{tabular}

Fonte: Elaboração dos autores.

No ano de 1984 verificou-se que toda a região lagunar encontrava-se resguardada pela presença de bancos arenosos, também foi observado todo o preenchimento da laguna pela planície de maré, que nesse ano já passa a ocupar uma área de $1,63 \mathrm{~km}^{2}$. No referido ano percebeu-se um discreto aumento na área colonizada por mangue, com área de $0,08 \mathrm{~km}^{2}$, esse fato pode estar associado à recente sedimentação da planície de maré o que ainda não havia favorecido a dispersão dos propágulos de mangue sobre o substrato (Figura 5 -B e Tabela 1). 
Na análise efetuada para o ano de 2014 a área total da Planície de maré sofreu redução de cerca de $68 \%$, com valor de área de $0,53 \mathrm{~km}^{2}$. Mesmo com a redução na área do substrato, a área de mangue aumentou, passando a ocupar $0,23 \mathrm{~km}^{2}$ da planície de maré. Esse aumento pode estar relacionado à estabilização do ambiente de Planície de maré, o que permitiu a fixação dos propágulos e desenvolvimento do Manguezal (Figura 5 -B e Tabela 1).

A evolução da planície de maré na desembocadura do rio Vaza Barris ocorreu de forma diferenciada da planície de maré da desembocadura do rio Sergipe. No caso do rio Vaza Barris o fator redução foi ocasionado pelas mudanças no posicionamento da Linha de costa na margem direita da desembocadura de influencia fluviomarinha, e não pelas pressões antrópicas, que se mostraram inexistentes até o ano analisado. A Figura 6 mostra o posicionamento da Linha de costa nos anos de 1971, 1984, 2004 e 2014. É possível verificar o recuo da laguna no sentido sudoeste da imagem (Figura 6), esse recuo está relacionado à migração do canal influenciado pelo fluxo fluvial e pela dinâmica dos deltas de marés vazantes, que ora atua no sentido de promover a progradação dos ambientes de sedimentação costeira (conforme explicado na introdução deste trabalho), ora atua na intensificação dos processos erosivos no local.

O fato das pressões antrópicas serem os principais condicionantes responsáveis pela diminuição da área da planície de maré na desembocadura do rio Sergipe, não significa que a área de estudo também não sofra a influência do recuo de linha de costa (e com isso da erosão costeira) como foi identificada na desembocadura do rio Vaza Barris. Trabalhos realizados por Rodrigues (2008); Santos (2012) apontaram que toda a margem direita da desembocadura sofreu com processos erosivos em médio prazo devido a mudanças na direção do talvegue do rio Sergipe associadas à dinâmica dos deltas de maré vazantes, grande parte desses processos erosivos foram intensificados devido à degradação da planície de maré que possuía a função de molhe hidráulico protegendo a linha de costa da Coroa do Meio. Bittencourt; Dominguez; Oliveira (2006) ressaltaram que as duas desembocaduras analisadas neste trabalho correspondem ao setor costeiro classificado como de elevada variabilidade.

De acordo com Shaeffer-Novelli; Citrón-Molero; Soares (2002) baseando-se em Thom (1982) os ambientes de planícies de marés possuem resistências e resiliências (capacidade de se recuperar de perturbações graves na paisagem) diferenciadas, conforme a predominância dos componentes da dinâmica fluviomarinha nas zonas estuarinas. Ambientes onde a energia das ondas predominam tendem a possuir baixa resistência a mudanças na paisagem e baixa resiliência; Ambientes que predominem alto fluxo fluvial e alta energia das ondas tendem a possuir médias resistências e resiliências; e Ambientes com predominância da influência do regime de marés tendem a possuir alta resistência e resiliência. Conforme foi verificado a partir dos resultados deste trabalho, a dinâmica costeira influenciou de forma determinante para a redução da área de planície 
de maré na desembocadura do rio Vaza Barris devido ao recuo de linha de costa influenciado pela dinâmica fluvial e marinha. Contudo é necessário reforçar que mesmo a planície de maré tendo reduzido sua área total a área colonizada por mangue aumentou, mesmo em face das mudanças promovidas na dinâmica fluviomarinha. A análise da resistência e resiliência na desembocadura do rio Sergipe, tomando como parâmetro os condicionantes físicos, não pôde ser efetuada tendo em vista que o fator antrópico constituiu elemento fundamental para diminuição da área total da planície de maré da Coroa do Meio.

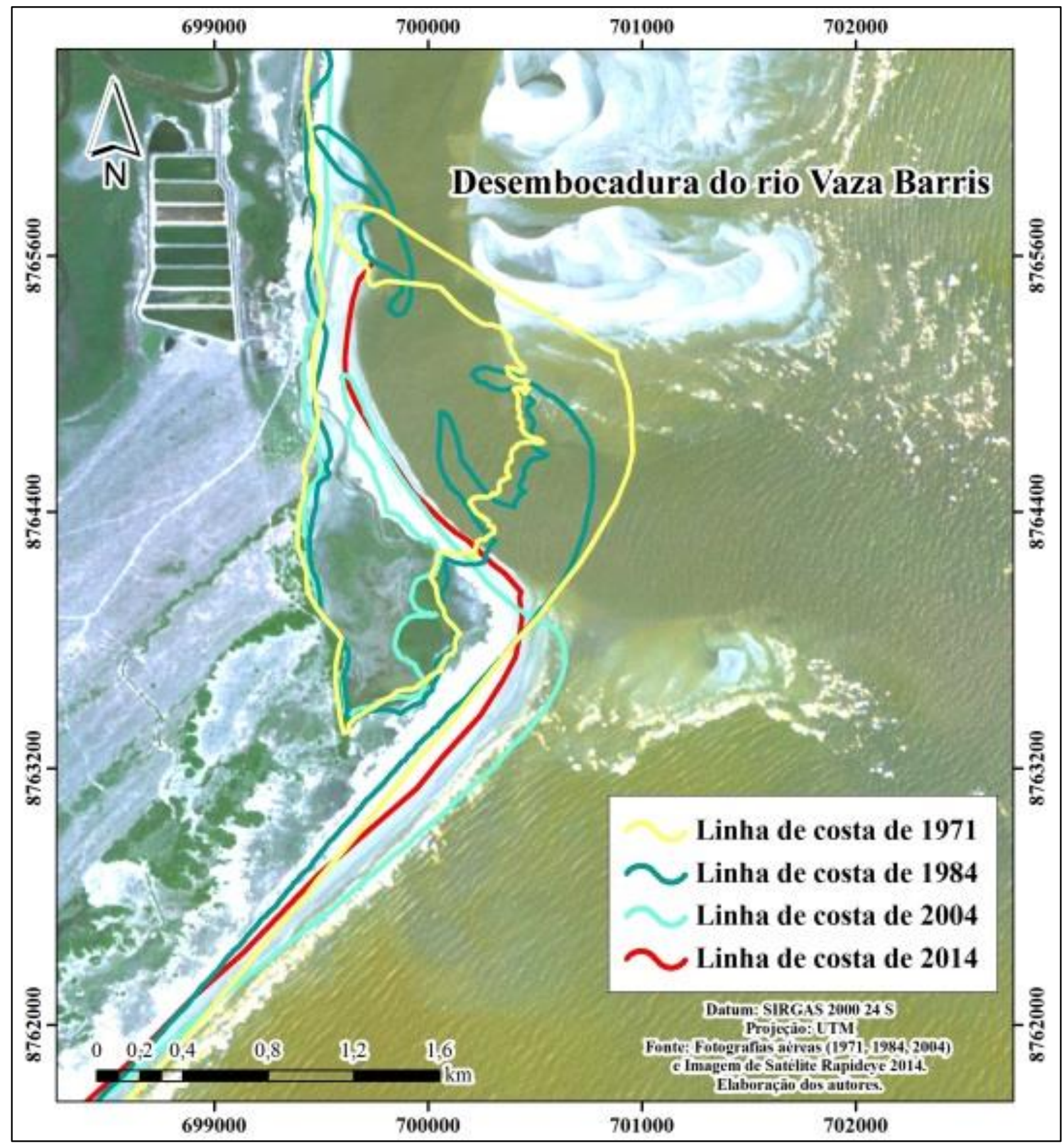

Figura 6 - Recuo de linha de costa na margem direita da desembocadura do rio Vaza Barris - Itaporanga D’Ájuda/SE. Fonte: Elaboração dos autores. 


\section{CONSIDERAÇÕES FINAIS}

A análise multitemporal da área de estudo revelou processos deposicionais recentes nas desembocaduras dos rios Sergipe e Vaza Barris que culminaram na formação de ambientes de planícies de marés e posteriormente na colonização pelo mangue, originando ecossistemas de manguezais.

A análise evolutiva revelou um ponto em comum, em todas as desembocaduras ocorreu redução na área total da planície de maré. Contudo, os processos que ocasionaram a redução da feição geomorfológica costeira foram diferenciados. Na desembocadura do rio Sergipe o fator condicionante foi a ação antrópica, representada pela urbanização do bairro Coroa do Meio em Aracaju/SE, nessa desembocadura o ambiente de planície de maré reduziu cerca de $48 \%$. Já na desembocadura do rio Vaza Barris (Itaporanga D’Ájuda) o fator condicionante para a redução da planície de maré foi a dinâmica fluviomarinha, promovendo o recuo de linha de costa reconfigurando a laguna que abriga o ambiente de planície de maré. Nesta última desembocadura mesmo o ambiente de planície de maré sofrendo redução a área de mangue aumentou quase 68\%, o que demonstra a resistência e a resiliência do ecossistema manguezal.

A análise evolutiva de ambientes de planícies de marés e ecossistemas manguezais associados se torna de extrema relevância para avaliação das respostas dos ambientes costeiros a possíveis mudanças na dinâmica costeira em escalas locais e globais e na avaliação da sua importância enquanto estabilizadora das regiões costeiras.

\section{REFERÊNCIAS}

ANGULO, R. J. O manguezal como unidade dos mapas geológicos. In: Simpósio de ecossistemas da costa sul e sudeste brasileira, v. 2, 1990, Águas de Lindóia. Resumos expandidos. São Paulo: ACIESP, 1990, p.54-62.

BITTENCOURT, A. C. S. P. ; MARTIN, L. ; DOMINGUEZ, J. M. L.; FleXOR, J. M. ; FERREIRA, Y. A.. Evolução Paleogeográfica Quaternária da Costa do Estado de Sergipe e da Costa Sul do Estado de Alagoas. Revista brasileira de geociências, v. 13, n. 2, p. 93-97, 1983.

BITTENCOURT, A. C. S. P.; DOMINGUEZ, J. M. L.; OLIVEIRA, M. B. Sergipe. In: MUEHE, D. (Org.). Erosão e Progradação do Litoral Brasileiro. Brasília-DF: Ministério do Meio Ambiente, 2006. p. 214-218.

CHAPMAN, V. J. Mangrove biogeography. Proc. Int. Symp. Biology and Management of Mangroves, v.1, 1975. p. 3-22. 
FITZGERALD, D. M. ; KRAUS, N. C.; HANDS; E. B. Natural Mechanisms of Sediment Bypassing at Tidal Inlets. US Army Corps of Engineers. ERDC/CHL CHETN-IV-30. December 2000, p.1-10.

MARTIN, L; SUGUIO, K; FLEXOR, J. M. As flutuações de nível do mar durante o quaternário superior e a evolução geológica de "deltas brasileiros". Boletim IG-USP, nº15. p.1 - 186, 1993.

MONTEIRO, M. da G. A restinga da Atalaia: Uma contribuição ao estudo do litoral sergipano. 1963. 50 f. Tese (Concurso a cátedra de Geografia) - Colégio Estadual de Sergipe, Aracaju, SE, 1963.

OLIVEIRA, L. S.; MELO e SOUZA, R. Morfodinâmica estuarina e variações do delta de marévazante no rio Vaza-barris, SE, Brasil. Revista Brasileira de Geomorfologia, São Paulo, v. 16 , n. 4 (Out/Nov) p.641-656, 2015.

PAJAK, M.J.; LEATHERMAN, S.The high water line as shoreline indicator. Journal of Coastal Research, 18(2). p. 329-337, 2002.

RODRIGUES, T.K. Análise das mudanças da linha de costa das principais desembocaduras do estado de Sergipe, com ênfase no rio Sergipe. 2008. 78f. Dissertação (Mestrado em Geologia) Universidade Federal da Bahia, Salvador, BA, 2008.

SANTOS, G. C. Derivações antropogênicas e Evolução do manguezal nos bairros 13 de julho e Jardins em Aracaju-SE. Revista Brasileira de Geografia Física. v. 7 n.02. p. 278-290, 2014.

SANTOS, G. C. Dinâmica da paisagem costeira da Coroa do Meio e Atalaia - Aracaju/SE. 2012. 152f. Dissertação (Mestrado em Geografia) - Universidade Federal de Sergipe, São Cristóvão, SE, 2012.

SCHAEFFER-NOVELLI, Y.; CITRÓN-MOLERO, G.; SOARES, M.L.G. Chapter 9: Mangroves as indicators of sea level. In: HEALY, T. ; WANG, Y.; HEALY, J. A. (ed.) Muddy Coasts of the World: Processes, Deposits and Function, Elsevier Science, 2002. p. 245 - 262.

THOM, B. G. Mangrove ecology: a geomorphological perspective. Mangrove ecosystems in Australia, structure, function and management (ed. by B. F. Clough). p. 3-17, 1982.

WANDERLEY, L. L. Paisagem da janela: esse nosso inconstante rio Sergipe e a evolução de sua Foz. In: ALVES, J.P.H. (Org.). Rio Sergipe: importância, vulnerabilidade e preservação/ Organização de José do Patrocínio Hora Alves. Aracaju-SE: Ós Editora, 2006. p. 167 - 194.

WOODROFFE, C. D. Geomorphology and development of mangrove swamps. Grand Cayman island, West Indies, Bulletin of Marine science, $n^{\text {o } 32, ~ v .2, ~ p .381 ~-~ 398, ~} 1982$.

ZENKOVICH, V. P. Processes of coastal development. London, 1967, 738 f.

Trabalho enviado em 02/11/2016 Trabalho aceito em 05/12/2016 